ACM International Conference Proceeding Series9 April 2018, Pages 49-532nd International Conference on Information System and Data Mining, ICISDM 2018; Florida Polytechnic UniversityLakeland; United States; 9 April 2018 through 11 April 2018; Code 137526

\title{
Master data management maturity model for the microfinance sector in Peru(Conference Paper)
}

- Zúñiga, D.V.aEmail Author,

- Cruz, R.K. ${ }^{a}$ Email Author,

- Ibañez, C.R. ${ }^{a}$ Email Author,

- Dominguez, F. ${ }^{\circ}$ Email Author,

- Moguerza, J.M. ${ }^{\circ}$ Email Author

- aUniversidad Peruana de Ciencias Aplicadas, Lima, Peru

- 'Escuela Superior de Ingenier a Informática, Universidad Rey Juan Carlos, Madrid, Spain

\section{Abstract_View references (21)}

The microfinance sector has a strategic role since they facilitate integration and development of all social classes to sustained economic growth. In this way the actual point is the exponential growth of data, resulting from transactions and operations carried out with these companies on a daily basis, becomes imminent. Appropriate management of this data is therefore necessary because, otherwise, it will result in a competitive disadvantage due to the lack of valuable and quality information for decision-making and process improvement. The Master Data Management (MDM) give a new way in the Data management, reducing the gap between the business perspectives versus the technology perspective In this regard, it is important that the organization have the ability to implement a data management model for Master Data Management. This paper proposes a Master Data management maturity model for microfinance sector, which frames a series of formal requirements and criteria providing an objective diagnosis with the aim of improving processes until entities reach desired maturity levels. This model was implemented based on the information of Peruvian microfinance organizations. Finally, after validation of the proposed model, it was evidenced that it serves as a means for identifying the maturity level to help in the successful of initiative for Master Data management projects. (C) 2018 Association for Computing Machinery.

SciVal Topic Prominence

Topic: Competitive intelligence | Industry | maturity model Prominence percentile: 90.401

Author keywords

DataMaster data managementMaturity modelMicrofinance 
Indexed keywords

Engineering controlled Data miningEconomicsFinanceInformation managementInformation systems terms:

Engineering uncontrolled Business perspectiveDataMaster data managementMaturity modelMicrofinan terms ImprovementQuality information

Engineering main heading: Decision making

- ISBN: 978-145036354-9

- Source Type: Conference Proceeding

- Original language: English

- DOI: $10.1145 / 3206098.3206127$

- Document Type: Conference Paper

- Sponsors:

- Publisher: Association for Computing Machinery 